\title{
A Perspective on Nominal Interest Rates
}

\author{
Fernando M. Martin, Senior Economist
}

nterest rates are at historic lows. The U.S. effective federal funds rate was near zero between late 2008 and late 2015 and has remained low since "liftoff" in December 2015. ${ }^{1}$ Other developed countries, such as Germany, Japan, and Switzerland, have recently sold new long-term debt at negative yields. This essay revisits some facts about interest rate behavior to provide context for the current situation.

Interest rates are at historic lows due to the combined effects of policy, regulation, and financial development.

The first figure shows monthly data for the effective federal funds rate and the yields on U.S. Treasury bonds at 1- and 10-year maturities since January 1955. All three rates show a similar long-term pattern: They were low until the mid-1960s. Then they started increasing, a trend that accelerated in the mid-1970s and reached its peak in the early 1980s. Since then, all the rates have been on a declining path.

The federal funds rate, which is an overnight rate, and the 1-year Treasury bond yield track each other very closely through the sample period, more so since the early 1980s. Although one can still argue about whether the Federal Reserve is dictating interest rates or, rather, accommodating market conditions at any particular time, the fact remains that short-term interest rates move closely in tandem.

In contrast, long-term interest rates, such as the 10-year Treasury bond yield, despite following the overall trend described previously, deviate markedly from short-term interest rates for significant periods of time. Since the 1980s, long-term interest rates appear to be well above short-term interest rates when the latter are temporarily low. In other words, the spread between short- and longterm interest rates is inversely related to the level of the short-term interest rate. This pattern can be clearly seen during the most recent recession, when short-term inter-

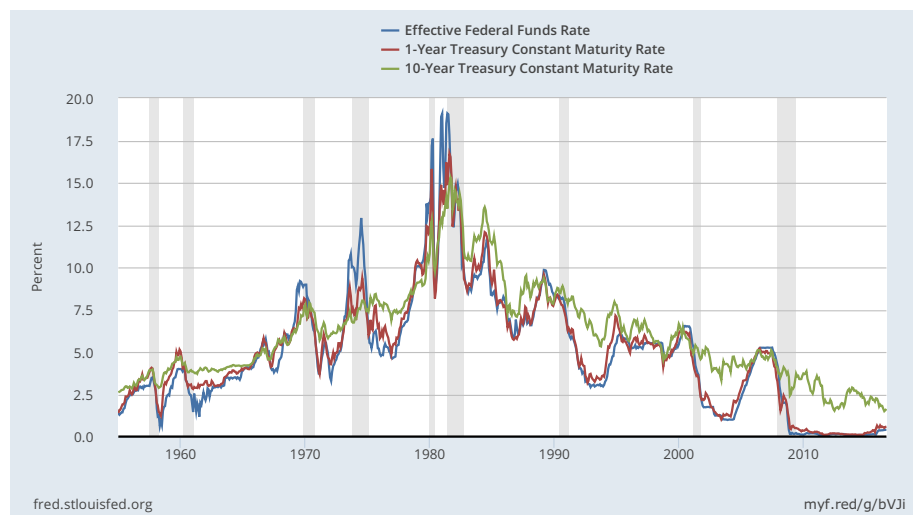

NOTE: The gray bars indicate recessions as determined by the National Bureau of Economic Research.

SOURCE: FRED ${ }^{\circledast}$, Federal Reserve Bank of St. Louis, November 2016; https://fred.stlouisfed.org/graph/?g=7Xhv.

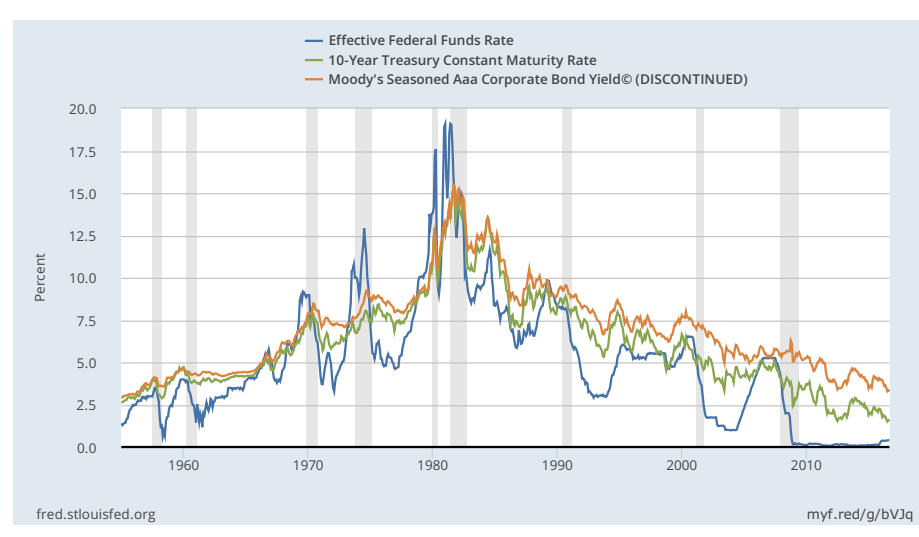

NOTE: The gray bars indicate recessions as determined by the National Bureau of Economic Research.

SOURCE: Board of Governors of the Federal Reserve System (US) and Moody's. Retrieved from FRED ${ }^{\circledR}$, Federal Reserve Bank of St. Louis, November 2016; https://fred.stlouisfed.org/graph/?g=7Xkw.

est rates declined sharply to near zero, while long-term interest rates appeared to continue their gradual downward path.

The second figure compares the Aaa corporate bond rate with the federal funds rate and the 10-year Treasury bond yield. The yields of long-term corporate bonds move in tandem with long-term government bonds. The differ- 


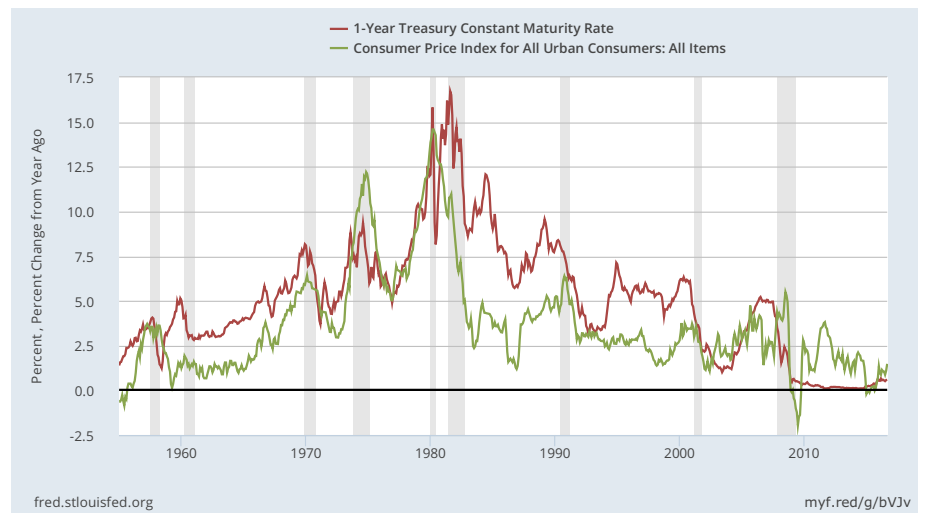

NOTE: The gray bars indicate recessions as determined by the National Bureau of Economic Research.

SOURCE: FRED ${ }^{\circledR}$, Federal Reserve Bank of St. Louis, November 2016;

https://fred.stlouisfed.org/graph/?g=7XIV.

ence between the two rates reflects both risk and liquidity premia. Mortgage rates have similar properties.

The third figure compares annual inflation, as measured by the year-over-year change in the consumer price index, with the 1-year Treasury bond yield. ${ }^{2}$ The rise in nominal interest rates until the early 1980s can be largely explained by an increase in inflation. Much of the subsequent steady decrease in interest rates can also be attributed to a decrease in inflation. Still, the real rate on government bonds (i.e., the difference between the nominal interest rate and inflation) has been trending downward as well. In fact, the real rate has been significantly negative since the end of the most recent recession.

What explains the decline in real rates? The jury is still out as economists study the issue and gather more evidence. A major factor is likely financial development. Government bonds have become easier to exchange and are a favorite option for corporations wanting to hold liquid assets. In other words, government bonds now resemble cash, which naturally implies low interest rates. ${ }^{3}$ For many purposes, especially at the corporate level, bonds are easier and safer to hold and use for transactions than cash or other money equivalents (e.g., demandable deposits). This may explain why, in the current low-inflation environment, the longterm government debt in some developed countries has a negative yield.

Another factor currently pushing nominal interest rates down is the "flight to safety." There has been a dramatic increase in the demand for safe assets since the world financial crisis of 2007-08 and with the concurrent development of large developing economies such as China. Arguably, the supply of safe assets has not kept pace with demand, which contributes to the decline in yields of government debt deemed to be safe.

Finally, financial regulation (e.g., the Basel Accords and the Dodd-Frank Act of 2010) has trended toward providing more incentives for banks and other financial intermediaries to hold a larger proportion of safe assets, especially government debt. These regulations have contributed to the overall growth in the demand for safe assets and, hence, the decline in their yields.

\section{NOTES}

\footnotetext{
${ }^{1}$ See also Andolfatto, David and Varley, Michael. "Not All Interest Rates May Rise after Liftoff." On the Economy (blog), Federal Reserve Bank of St. Louis, February 9, 2016; https://www.stlouisfed.org/on-the-economy/2016/february/not-all-interest-rates-rise-liftoff.

${ }^{2}$ Comparing two yearly rates removes the potential effect of the term premium.

${ }^{3}$ If cash and bonds were perfect substitutes (i.e., perfectly indistinguishable for practical purposes), then the interest rate on bonds should be zero.
} 